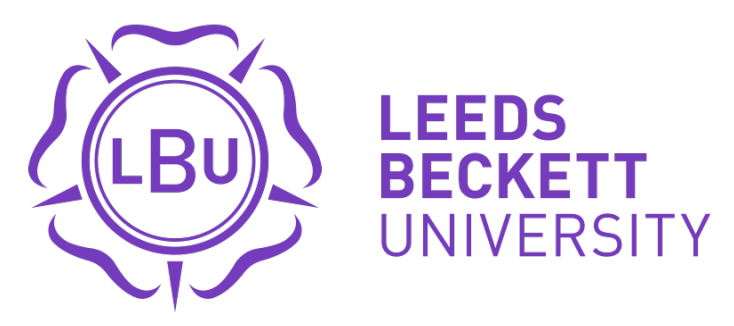

Citation:

Čadek, M and Flint, SW and Tench, R (2020) Delivery of the National Child Measurement Programme in England. Public Health Nutrition. pp. 1-21. ISSN 1368-9800 DOI: https://doi.org/10.1017/s1368980020004991

Link to Leeds Beckett Repository record:

https://eprints.leedsbeckett.ac.uk/id/eprint/7323/

Document Version:

Article (Accepted Version)

Creative Commons: Attribution-Noncommercial-No Derivative Works 4.0

The aim of the Leeds Beckett Repository is to provide open access to our research, as required by funder policies and permitted by publishers and copyright law.

The Leeds Beckett repository holds a wide range of publications, each of which has been checked for copyright and the relevant embargo period has been applied by the Research Services team.

We operate on a standard take-down policy. If you are the author or publisher of an output and you would like it removed from the repository, please contact us and we will investigate on a case-by-case basis.

Each thesis in the repository has been cleared where necessary by the author for third party copyright. If you would like a thesis to be removed from the repository or believe there is an issue with copyright, please contact us on openaccess@leedsbeckett.ac.uk and we will investigate on a case-by-case basis. 


\section{Delivery of the National Child Measurement Programme in England}

$$
\text { Martin Čadek, }{ }^{1} \text { Stuart W. Flint, }{ }^{2,3} \text { Ralph Tench }{ }^{4}
$$

${ }^{1}$ Carnegie School of Sport, Leeds Beckett University, United Kingdom

${ }^{2}$ School of Psychology, University of Leeds, Leeds, UK, LS2 9JT

${ }^{3}$ Scales Insights, Nexus, University of Leeds, Leeds, UK, LS2 3AA

${ }^{4}$ Leeds Business School, Leeds Beckett University, United Kingdom

Corresponding author: Mr Martin Čadek, School of Sport, Leeds Beckett University, Leeds, UK, LS6 3QS M.Cadek@ @leedsbeckett.ac.uk

Short title: Delivery of the National Child Measurement Programme in England

Acknowledgements: The NCMP team at Public Health England for their support with data collection.

Financial Support: Not applicable.

Conflict of Interest: None.

Authorship: Martin Čadek, principal investigator, writing, data collection, and analysis. Stuart W. Flint, writing and reviewing. Ralph Tench, writing and reviewing.

Ethical Standards Disclosure: This study was conducted according to the guidelines laid down in the Declaration of Helsinki and all procedures involving research study participants were approved by the Leeds Beckett University ethics committee. Written informed consent was obtained from all participants.

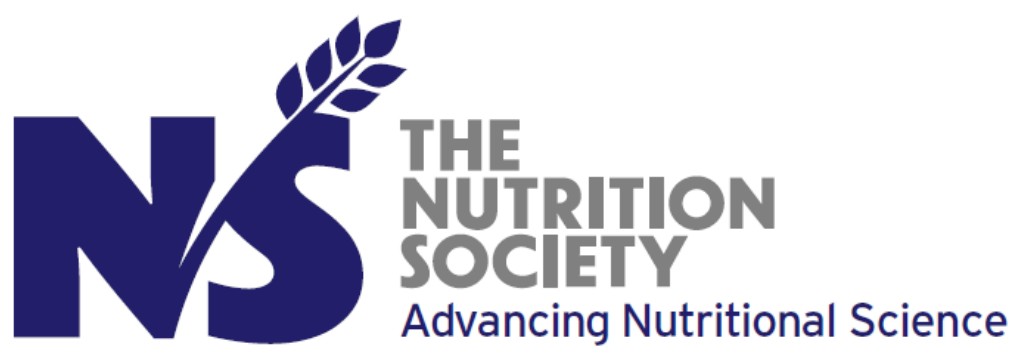

This is an Accepted Manuscript for Public Health Nutrition as part of the Cambridge Coronavirus Collection. This peer-reviewed article has been accepted for publication but not yet copyedited or typeset, and so may be subject to change during the production process. The article is considered published and may be cited using its DOI 10.1017/S1368980020004991

Public Health Nutrition is published by Cambridge University Press on behalf of The Nutrition Society 


\begin{abstract}
Objective: The National Child Measurement Programme (NCMP) is a mandatory initiative delivered in England to children in reception and year 6. To date, no research has explored the methods used to deliver the NCMP by Local Government Authorities (LGA) across England.
\end{abstract}

Design: An online survey was administered between February 2018 and May 2018 to explore the delivery of the NCMP across the 152 LGAs in England and disseminated using non-probability convenience sampling.

Setting: LGAs received an anonymous link to the survey.

Participants: A total of 92 LGAs participated in the survey.

Results: Most LGAs who responded provide result feedback (86\%), a proactive follow-up (71\%) and referrals to services (80\%). Additionally, $65 \%$ of the authorities tailor Public Health England specimen result letters to suit their needs, and $84 \%$ provide attachments alongside. Out of $71 \%$ of LGAs who provide proactive follow-up, 19 (29\%) provide the proactive follow-up only to upper weight categories, and only $4(6 \%)$ include Healthy Weight category with other categories in proactive follow-up. Regarding the service availability for children, out of $80 \%$ of LGAs who indicated that services are available, $32(43 \%)$ targeted solely upper weight categories while the other 42 (57\%) offered services across all weight categories. Finally, most LGAs (88\%) commission providers to manage various parts of the NCMP.

Conclusions: The results show that LGAs in England localise the NCMP. Further guidance regarding standards of best practice would help LGAs to find the most suitable localisation out of various options that exist across other LGAs.

Keywords: Childhood Obesity; National Child Measurement Programme; Policy; Local Government Authority 


\section{Accepted manuscript}

\section{Introduction}

The World Health Organization described childhood obesity as "one of the most serious public health challenges of the $21^{\text {st }}$ century"(1). This is due to the increasing prevalence of childhood obesity and associated physical and psychological health decrements. In response, national Governments and healthcare organisations have developed initiatives to monitor the prevalence and develop interventions. For instance, the UK Government's 'Childhood Obesity; a plan of action chapter 2' stated that there is a national ambition to halve childhood obesity and to significantly reduce the gap in prevalence between children in the most and least deprived areas by $2030^{(2)}$.

An initiative developed in England is the National Child Measurement Programme (NCMP) which is a mandatory programme delivered to all children in the first and final year of primary school (aged 4-5 and 10-11 years) whose parents/guardians have not opted-out ${ }^{(3)}$. The programme was originally developed as a method of monitoring children's weight status and has been delivered predominantly in primary school settings in England. Where schools opt-out from delivering the NCMP on their premises, nearby locations such as village halls are utilised. The programme has three phases; pre-measurement, where parents are contacted by their Local Government Authority (LGA) to inform parents/guardians about the programme including an opportunity to opt-out; the measurement, where children are measured for their height and weight which is translated into BMI z-scores and recorded in a national database (this provides national statistics for childhood overweight and obesity); and post-measurement, where parents/guardians are contacted by their LGA, typically providing an overview and relevant information (a feedback/the result letter) about their child's weight status. Nationally, the programme has $95 \%$ uptake equating to over 1 million children measured each year ${ }^{(4)}$. Out of the three phases, only the pre-measurement phase is mandated and LGA are required to inform parents according to The Local Authority (Public Health, Health and Wellbeing Boards and Health Scrutiny) Regulations $2013^{(5)}$ The provision of the results is voluntary but recommended by the British Government ${ }^{(6)}$ who also ensured that the legislative changes enabled to issue results to parents from $2008 / 2009^{(7-9)}$. These changes have evolved the programme from 
monitoring to a screening initiative ${ }^{(10-12)}$. Lastly, proactive follow-up of children who fall into the extremely low and high BMI centiles is recommended by the operational guidelines developed at the Public Health England (PHE) $)^{(3)}$.

Previous research regarding the NCMP has predominantly focused on the aspects related to the results feedback. For example, Nnyanzi et al. ${ }^{(7)}$ interviewed parents of children in the Reception and Year 6 who received the Overweight results and identified a range of behaviours (16 parents; female $=13$, low socioeconomic status $(\mathrm{SES})=8$ ) such as being shocked, denying the results, or fear or help-seeking (Nnyanzi et al., 2016). Gainsbury and Dowling ${ }^{(13)}$ described parental experience regarding the feedback for children in the Reception year using four focus groups (18 parents). Their results showed that parents commonly rejected the results letter for children identified as Overweight as they have felt the result was intended primarily for parents other than themselves and perceived the feedback as patronising and offensive $^{(13)}$.

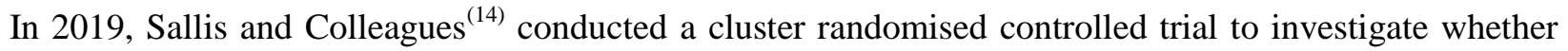
the uptake to children's weight management services can be increased by modifying the result letters. They have found a small effect between the intervention (4.33\% chance of uptake) and control group (2.19\% chance of uptake) among 2642 parents $^{(14)}$. In other work examining the impact of behaviour change from the parent feedback from the NCMP, Viner et al. reported that feedback has a positive effect on parental intentions to change behaviour; however, it often does not translate into the actual behaviour change ${ }^{(15)}$. Additionally, in their study, they have found that parents consult the results not only with various professionals such as GPs and school nurses but also use informal sources from the internet.

To our knowledge, there is no published data or research on the methods used to deliver the NCMP across the 152 LGAs in England and the PHE guidance to LGAs regarding the delivery of the NCMP allows for a varied approach, meaning schools, parents and families are likely to have varied experiences ${ }^{(3,16,17)}$. Thus, this study aimed to explore the delivery and implementation of the NCMP in England. 


\section{Accepted manuscript}

\section{Method}

Design

An online survey to explore the delivery of the NCMP was developed, comprising 59 questions. Most included an option to select "I don't know" or "Other". Where "Other" was selected, LGA representatives were asked to provide further details in an open-ended question.

The survey consisted of 5 blocks of questions: 1) opt-out of NCMP; 2) Parents' result feedback; 3) Proactive follow-up; 4) Available services; and 5) sociodemographic and supplementary information. Where appropriate, LGA representatives were able to skip questions. Three versions of the survey were piloted with a convenience sample $(n=35)$ of LGA Health and Wellbeing Board Commissioners from across England, representatives of PHE and university researchers before releasing the final version.

The final survey questions were selected as part of in-depth consultations with the NCMP team at PHE and representatives of selected LGA who volunteered to peer-review each survey iteration. The most significant change was reducing the number of questions from 122 to 59. Additionally, the selected experts had practical experience with the NCMP which helped to modify the survey terminology. For example, initially, we've used the term "routine feedback" but after the consultation was replaced with “parents results letter".

As part of the survey, LGA representatives were asked to upload their most recent NCMP documentation i.e. pre-measurement letters, result letters, any additional attachments sent with the letters. To increase the participation rate, all representatives were entered into a prize draw to attend an international conference or one of two $£ 100$ amazon gift vouchers.

\section{Sampling}

Conventional sample size estimations for finite population was used where the margin of error was $\mathrm{z} \times \mathrm{SE}$ $\leq 0.05$ (up to $5 \%)^{(18)}$. The finite population correction formula was applied on calculated sample size from infinite population formula based on the margin of error formula ${ }^{(19)}$. This has yielded the required sample size of 110 after rounding. Non-probability convenience sampling ${ }^{(20,21)}$ was used, which was facilitated 
throughout PHE Regional centres. As shown in Supplementary Materials - Figure 5, we have achieved response rates between $53 \%$ to $69 \%$ across four geographical regions (London, Midlands and the East, South, the North) of England (see also Supplementary Materials - Figures 6 to 8 for additional demographic details).

\section{Procedure}

After institutional ethics clearance, LGAs were contacted via emails to complete the survey between February 2018 and May 2018. In agreement with PHE's NCMP team, emails were delivered to LGAs with the assistance of PHE Regional Offices. The email asked for a representative from each LGA who has a good understanding of the operational delivery and access to the NCMP documentation to complete the survey. Freedom of Information requests was sent to 60 LGAs in June 2018 who did not upload the NCMP documentation within the survey; 55 LGAs provided the documents.

\section{Data Analysis}

Descriptive analysis of the survey data was produced to represent LGA delivery of the NCMP. Results are presented as frequencies and percentages, with supplementary visual representations using $\mathrm{R}$ software environment for statistical computing version 4.0.0 (2020-04-24), R Studio 1.3.959 and the Grammar of Graphics 2 (ggplot2) $)^{(22)}$.

\section{Results}

\section{Descriptives}

Ninety-two (out of 152; 61\%) LGA representatives completed the survey (assumed margin of error was z $\times \mathrm{SE} \leq 0.10$ or $10 \%)$. Each LGA selected their representative; see Supplementary Materials - Figure 1. A further 23 LGAs provided NCMP documentation after Freedom of Information requests (i.e. 115 LGAs). For the majority of sampled $(\mathrm{n}=92)$ LGAs the NCMP delivery is commissioned to a provider 
organisation (The provider is any organisation supporting the NCMP that has been commissioned by an LGA and is not the LGA itself.) (88\%), then In-house (11\%), Other (4\%) and I don't know (0\%).

Figure 1 provides an overview of the tasks and responsibilities for NCMP delivery. Panel A represents those that are managed by LGAs, Panel B shows the responsibilities managed by a commissioned provider and Panel $\mathrm{C}$ indicates what responsibilities are shared amongst the two. The graphs are set visualisations and are analogous to Venn diagrams where the upper section of the visualisation indicates the number of responses (NR) for a given combination of (sets) responsibilities ${ }^{(23,24)}$.

The two most common responsibilities (sets) were commissioning the NCMP (NR = 30) and sending school feedback letters $(\mathrm{NR}=29)($ Panel A, Figure 1$)$.

In comparison, commissioned providers were tasked to manage various responsibilities with the dominant set including all responsibilities except for commissioning the NCMP, sending school feedback letters, and developing result letters for parents $(\mathrm{NR}=13)$ (Panel B, Figure 1).

By far the most common shared responsibility was developing result letters for parents $(\mathrm{NR}=27)$, and thus, LGAs and providers co-author the NCMP result letters which are delivered to parents (Panel C, Figure 1).

\section{Pre-measurement information}

Legally, all LGAs must inform parents and offer them an opportunity to opt their child out of the NCMP. Therefore, it was assumed that all LGAs perform this duty.

The most common method of informing parents about the NCMP measurements among the participating LGAs was via children's school bags $(\mathrm{N}=64 ; 70 \%)$, followed by postal services $(\mathrm{N}=23 ; 13 \%)$; see Figure 2 - right-hand side. However, LGAs often facilitated the delivery of information using multiple methods as per Figure 2 - left-hand side. The letters and postal services were the most common combination of sets indicating that these are the preferred methods of delivering the pre-measurement information $(\mathrm{NR}=39$ and $\mathrm{NR}=14$ respectively); Figure $2-$ left-hand side. 


\section{Accepted manuscript}

LGAs primarily use the PHE specimen; however, the majority $(\mathrm{N}=55 ; 60 \%)$ modify it. Five representatives indicated they had never seen the specimen. Inductive content analysis ${ }^{(25)}$ of the reasons LGAs change the PHE pre-measurement specimen letter indicated 4 themes - clarifications, language, localisation, and user-driven; see Supplementary Materials - Table 1.

Finally, LGAs were asked whether they provide attachments alongside the opt-out letter: 45 (49\%) included attachments; 33 (36\%) did not, and $14(15 \%)$ did not provide an answer.

\section{Result feedback to parents}

Seventy-nine (86\%) of sampled LGAs provide result feedback to parents. Figure 3, Panel B shows that of those LGAs, most $(\mathrm{NR}=55)$ delivered results to all weight categories; however, 14 LGAs indicated that they prioritise children outside Healthy Weight category, 4 indicated they only target the upper weight category with the rest of the representatives indicating mixed response pattern.

The most common option from the sum of all options (i.e., sum of all distinct options in sets) describing the methods for delivering the result feedback to parents was postal services (i.e., letters, $\mathrm{N}=69,75 \%$ ), followed by phone calls $(\mathrm{N}=20,22 \%)$. Additionally, $84 \%$ (66) of LGAs provide an attachment (e.g. Change4Life Leaflet) alongside result.

The most common set of delivery methods (see Figure 3, Panel A) were postal services $(\mathrm{NR}=45)$, followed by postal services combined with phone calls $(\mathrm{NR}=15)$. Four LGAs indicated that they only deliver via children's school bags. In terms of alternative delivery methods for parents' results feedback, the following responses were recorded: * "Coffee mornings" (LGA from London), "Home visits" (LGA from Midlands and the East), “We will be starting to utilise Parents 'Chat Health' which is an anonymous texting system for parents to raise concerns with the school nursing service" (LGA from the Midlands and East), "We highly recommend that the school texts the parents of Year 6 children to inform them to come and collect their child's letters by a certain date. If they do not get collected, they will then go out in the children's school bag." (LGA from the North) 
The final comment by one of the representatives indicates that children's school bags may be a viable method if LGAs do not regularly use postal services. In this case, parents are encouraged to gather the result feedback (i.e., letters) themselves from their school but if they do not, the LGA will use the child's school bag method. This may also be rationalised by cost-effectiveness, despite PHE discouraging this delivery method.

Some LGAs do not provide the result feedback to all parents; these reasons included prioritising children perceived to be of most need $(21 ; 47 \%)$, staff capacity to implement this mechanism $(6 ; 13 \%)$, and lack of service provision $(2 ; 4 \%)$ :

"We only send letters to underweight, overweight and very overweight. We had altered the letter a few times but still receive negative feedback from parents regarding the wording of the letter." (LGA from the North)

"Parents have to request through a website for the height and weight of the child and that only appears on the letter sent to them. Some people loose [sic] these letters and struggle to find the information they need." (LGA from the South)

"Parents are advised that they can call the Public Health Commissioner for Children and Young People to find out their child's results." (LGA from London)

Fifty-one $(65 \%)$ of sampled LGAs use PHE's specimen result letter but tailor it to their needs; $23 \%$ ( $\mathrm{N}=$ 18) use it and do not alter it, and $11 \%$ do not use it $(\mathrm{N}=9)$. Reasons for changing the PHE specimen result letter centred on five main themes - clarifications, design, language, localisations, user-driven see Supplementary Materials - Table 2.

Finally, we asked the representatives how parents can contact them after receiving the results see Supplementary Materials - Figure 2. Most of the representatives indicated that the two most common 
methods are phone number $(\mathrm{NR}=30)$ and a combination of phone number with email $(\mathrm{NR}=17)$. These contact options are listed within the result feedback (i.e., letters) parents receive.

\section{Proactive follow-up}

Sixty-five (71\%) of the participating LGAs proactively follow-up (i.e., proactive follow-up involves contacting a parent or carer to offer them personalised advice and services) with parents, 21 (23\%) do not, and $6(7 \%)$ did not know. LGAs were asked who receives the follow-up, what delivery methods they use, and their reasons for targeting weight categories that they indicated. Sixty-five LGAs who indicated that they deliver proactive follow-up indicated that they target parents of children identified within the Overweight and Very Overweight $(\mathrm{N}=19,21 \%)$; Underweight, Overweight and Very Overweight $(\mathrm{N}=$ 19, 21\%); and Underweight and Very Overweight $(\mathrm{N}=11 ; 12 \%)$ ranges (see Figure 4, Panel B). Thus, proactive follow-up is focused primarily on groups excluding Healthy Weight; see Figure 4, Panel B.

The most common set of methods for proactive follow-up were phone calls $(\mathrm{N}=28)$ or phone calls and postal services $(\mathrm{N}=14)$; see Figure 4 , Panel A. Where proactive follow-up was not delivered to all parents of children participating in the NCMP, the most common set of reasons was the combination of cost-funding and staff capacity to implement $(\mathrm{N}=16)$; see Figure 4, Panel C.

\section{Services}

Seventy-four (80\%) of the participating LGAs reported having any services (as part of healthy weight care-pathways; Tier 1, 2, 3, and universal) available for parents or carers and their Reception year and Year 6 children. Only 4 LGA representatives reported that there is no service available, which was primarily due to cost implications (1 representative was not sure). The available services were offered to children with various NCMP weight classification and the classifications were often combined. Of the 74 LGAs that reported available services, 32 (35\%) indicated they offered combined access for children 
identified within the Overweight and Very Overweight ranges, while 20 (22\%) offer combined access to all weight groups; see Figure 5. Eleven (12\%) LGAs offered services to combination of all weight classifications except for children identified within the Healthy Weight range.

LGAs that provide services but do not target all weight groups $(\mathrm{N}=54)$ were asked for the reasons they restrict service access. Supplementary Materials - Figure 3, Panel A shows that the most common reason was lack of funding $(\mathrm{NR}=6)$ and other $(\mathrm{NR}=11)$; for example: "Underweight children are supported through their GP and not our Healthy Lifestyle service”. Supplementary Materials - Figure 3, Panel B extends to LGAs which indicated they do not provide any services at all. This was relevant to 4 out of 5 LGAs and the cost of funding was indicated 3 times.

\section{Comparing the PHE regions}

Finally, we show the selection of the key plots across all phases of the NCMP; however, this time we also add a split between PHE regions (London, Midlands and the East, South, and the North) to allow comparison between parts of England in the participating LGAs. Supplementary Materials - Figure 4 shows how is the measurement information with opt-out and the result feedback delivered (A, B), and which children are usually targeted in proactive follow-up and eligible for services $(\mathrm{C}, \mathrm{E})$. There are no remarkable regional differences in how the NCMP is delivered in the regions.

\section{Discussion}

The current study aimed to explore the delivery of the NCMP by LGAs across England. The study has highlighted the varied practice, responsibilities, and ultimately, experiences that parents and families have that participate in the NCMP.

The current study identified a high proportion of LGAs commission the NCMP to provider organisations, modify the PHE specimen result letter and include further information about local services. This, as well as the varied modes of delivering the NCMP, and in some instances not performing some of the 
recommended NCMP mechanisms (e.g. proactive follow-up) due to factors such as cost, raises questions about the comparable nature of the NCMP and the ability to highlight good practice that can be translated to other LGAs ${ }^{(3)}$.

Furthermore, methods of delivering the pre-measurement information varied; the most common was in children's school bag. Most LGAs alter the PHE specimen letter, with a very small percentage reporting that they had never seen it.

Most result feedback is posted as letters to parents, with few sending the letter via children's school bag which does not adhere to PHE guidance ${ }^{(3)}$. Alongside the result feedback, most LGAs include attachments such as healthy eating guides, information about local services, and Change4Life leaflets. Many LGAs do not provide result feedback to all children, and in most cases, parents of children identified within the Healthy Weight range do not receive the feedback.

The most common reason that LGAs do not provide proactive follow-up and do not have child weight management services was cost. Regrettably, the provision of the NCMP relies on printed materials and electronic delivery methods remain underutilised, as evidenced by our results. We believe that additional support and guidance needs to be available for LGAs to help them implement electronic delivery methods; and thus, reduce the cost of the NCMP.

Future work should explore the impact of the varied practice including the modifications to the NCMP result feedback. The feedback element of the NCMP has been criticised as a cause of distress to parents $^{(7,13,26)}$. A paucity of research has explored parents experiences to the varied feedback content and given the potential impact of this NCMP element, further work is warranted. One study that has explored the impact of NCMP feedback reported that the letters can be used to nudge parents, leading to a small increase in service uptake ${ }^{(14)}$.

Research suggests that parents have various preferences regarding the feedback and these should be considered within NCMP feedback (e.g., for example, timing, terminology, literacy level, or tone) ${ }^{(12)}$. 
Since LGAs are free to modify the feedback information, there should be a discussion about how to best share the feedback. Unfortunately, this topic appears to be underestimated in the available guidelines ${ }^{(3,27)}$. For example, the conversational framework guidelines state that "A parent's beliefs and culture will influence how they respond to NCMP feedback"(27) (p. 13). While the guidelines acknowledge that parents may experience distress, it does not recognise that the content of the letters or the way the feedback is shared may be the cause this, and thus, does not provide support to LGAs on the best practice that could be followed taking local arrangements into account ${ }^{(27)}$.

This study is not without limitations. The current sample of LGAs does not cover all potential variations of the NCMP implementation. From all possible LGAs (152), 92 agreed to participate in the survey While we believe the study brings representative findings given the response rates across the four PHE regions varied from 53 to $69 \%$, the non-probability sampling technique is a limitation that should be considered when interpreting the study findings. Additionally, some LGAs may not have been comfortable sharing their data or were experiencing changes which meant they were unable to provide data at the time of the study. Finally, the survey focused on the perspective of LGA representatives; we did not explore the perspectives of other stakeholders such as schools, providers, or parents in this survey.

The study collected data between February 2018 and May 2018. On 14 February 2018, PHE introduced the new version of the result feedback (i.e., letters) which replaced the version primarily used between years 2014 - 2017, but not all LGAs have been able to use the latest version ${ }^{(3)}$. Additional updates to the operational guidelines were introduced in the same year; therefore, some of the practical and local changes may have happened in the following year due to the introduced changes ${ }^{(3)}$.

The study findings highlight that NCMP delivery is varied, and that further guidance regarding standards of best practice would help LGAs to find the most suitable localisation from the various options that exist. Additionally, since the majority of LGAs work with external providers, further guidance should be available to support these collaborations. We believe that each part of the NCMP process should be treated as a longer-term relationship building between parents, LGAs, and potential service providers. 
After all, the relationship between provider and parents is one of the key elements of addressing childhood obesity ${ }^{(28)}$. Finally, only a limited number of LGAs currently benefit from electronic delivery of the NCMP, which may support with funding challenges.

In conclusion, this study provides the first insights into the design implementation and delivery of the NCMP in England. Key findings show that there is varied practice, and therefore experiences, for parents and children that participate. 


\section{References}

1. World Health Organization (2020) Childhood overweight and obesity. World Health Organ. http://www.who.int/dietphysicalactivity/childhood/en/ (accessed May 2020).

2. Department of Health \& Social Care (2018) Childhood obesity: a plan for action, chapter 2. Department of Health and Social Care London.

3. Public Health England (2019) National Child Measurement Programme Operational Guidance 2019. 1-64. London: Public Health England: London.

4. Public Health England (2020) Public Health Profiles. https://fingertips.phe.org.uk (accessed April 2020).

5. UK Parliament (2013) The Local Authority (Public Health, Health and Wellbeing Boards and Health Scrutiny) Regulations 2013. Queen's Printer of Acts of Parliament.

6. Department of Health (2008) Healthy weight, healthy lives: a cross-government strategy for England. HM Gov., 1-56.

7. Nnyanzi LA, Summerbell CD, Ells L, et al. (2016) Parental response to a letter reporting child overweight measured as part of a routine national programme in England: results from interviews with parents. BMC Public Health 16, 846.

8. Lake J (2009) The development of surveillance and screening for childhood obesity in the UK. Crit. Public Health 19, 3-10.

9. Department of Health (2007) Legislative changes to the national child measurement programme (NCMP). http://webarchive.nationalarchives.gov.uk/+tf_/http://www.dh.gov.uk/en/Publichealth/Healthimprove ment/Healthyliving/DH_080606.

10. Grimmett C, Croker H, Carnell S, et al. (2008) Telling Parents Their Child's Weight Status: Psychological Impact of a Weight-Screening Program. Pediatrics 122, e682-e688.

11. Nnyanzi LA (2012) The national child measurement programme: its value and impact. Doctoral Thesis, Teesside University.

12. Ames H, Mosdøl A, Blaasvær N, et al. (2020) Communication of children's weight status: what is effective and what are the children's and parents' experiences and preferences? A mixed methods systematic review. BMC Public Health 20, 574.

13. Gainsbury A \& Dowling S (2018) 'A little bit offended and slightly patronised': parents' experiences of National Child Measurement Programme feedback. Public Health Nutr.

14. Sallis A, Porter L, Tan K, et al. (2019) Improving child weight management uptake through enhanced National Child Measurement Programme parental feedback letters: A randomised controlled trial. Prev. Med. 121, 128-135. Elsevier.

15. Viner RM, Kinra S, Christie D, et al. (2020) Improving the assessment and management of obesity in UK children and adolescents: the PROMISE research programme including a RCT. Programme Grants Appl. Res. 8. National Institute for Health Research. 
16. Public Health England (2017) National Child Measurement Programme Operational Guidance 2017. 1-46. Public Health England: London.

17. Public Health England (2018) National Child Measurement Programme Operational Guidance 2018. 1-58. Public Health England: London.

18. Ramachandran K \& Tsokos C (2015) Mathematical Statistics with Applications in R. 2nd ed. Elsevier Academic Press Inc.

19. Diez D, Barr C \& Cetinkaya-Rundel M (2014) Introductory Statistics with Randomization and Simulation. 1st ed.

20. Etikan I, Musa SA \& Alkassim RS (2016) Comparison of convenience sampling and purposive sampling. Am. J. Theor. Appl. Stat. 5, 1-4. New York.

21. Levy PS \& Lemeshow S (2008) Sampling of Populations: Methods and Applications. John Wiley \& Sons.

22. Wickham H (2016) ggplot2: elegant graphics for data analysis. Springer.

23. Conway JR, Lex A \& Gehlenborg N (2017) UpSetR: an R package for the visualization of intersecting sets and their properties. Bioinformatics 33, 2938-2940 [Hancock J, editor].

24. Lex A, Gehlenborg N, Strobelt H, et al. (2014) UpSet: Visualization of Intersecting Sets. IEEE Trans. Vis. Comput. Graph. 20, 1983-1992.

25. Braun V \& Clarke V (2006) Using thematic analysis in psychology Using thematic analysis in psychology. Qual. Res. Psychol. 0887, 77-101.

26. Gillison F, Beck F \& Lewitt J (2014) Exploring the basis for parents' negative reactions to being informed that their child is overweight. Public Health Nutr. 17, 987-997.

27. Chadwick P, Clark J \& Gahagan A (2019) National Child Measurement Programme: conversation framework. Public Health England.

28. Sjunnestrand M, Nordin K, Eli K, et al. (2019) Planting a seed - child health care nurses' perceptions of speaking to parents about overweight and obesity: a qualitative study within the STOP project. BMC Public Health 19, 1494. 
Accepted manuscript
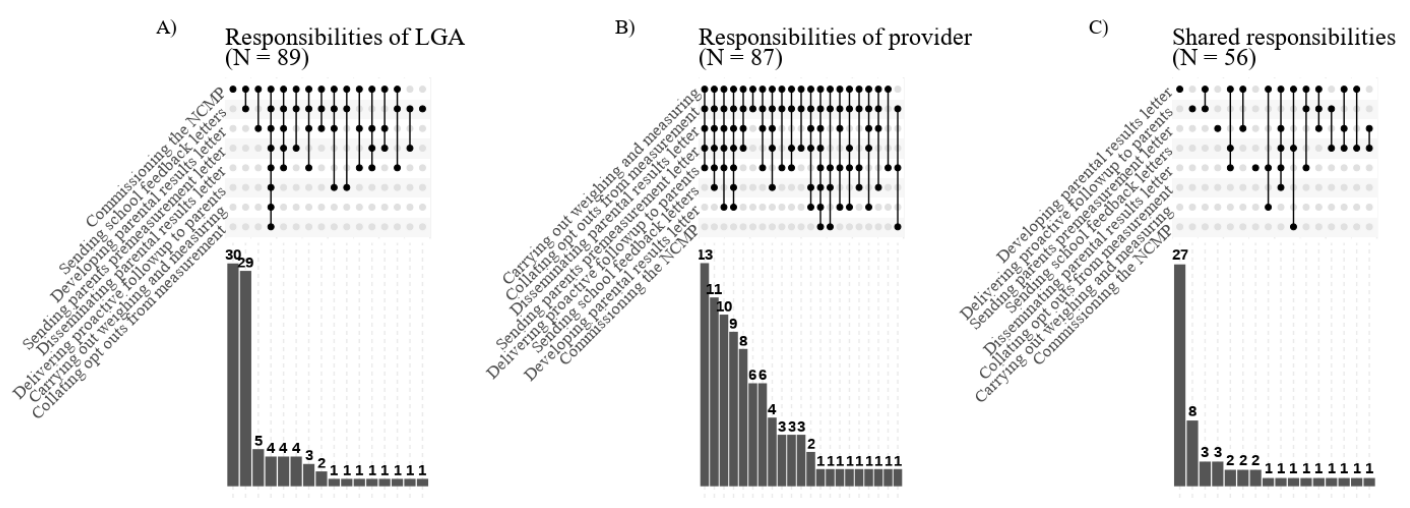


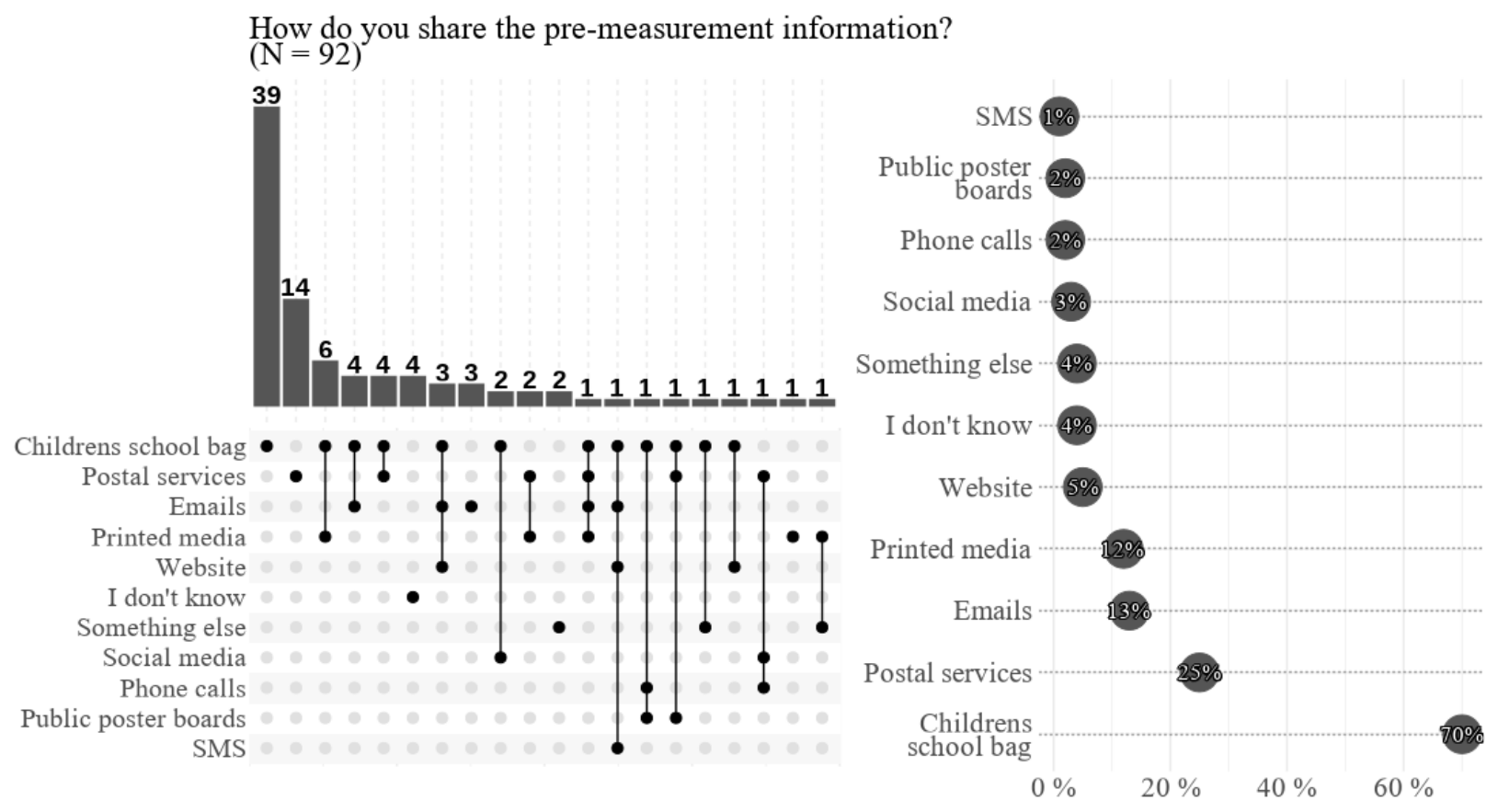


Accepted manuscript

A) How do you share the results with parents?
$(\mathrm{N}=79)$

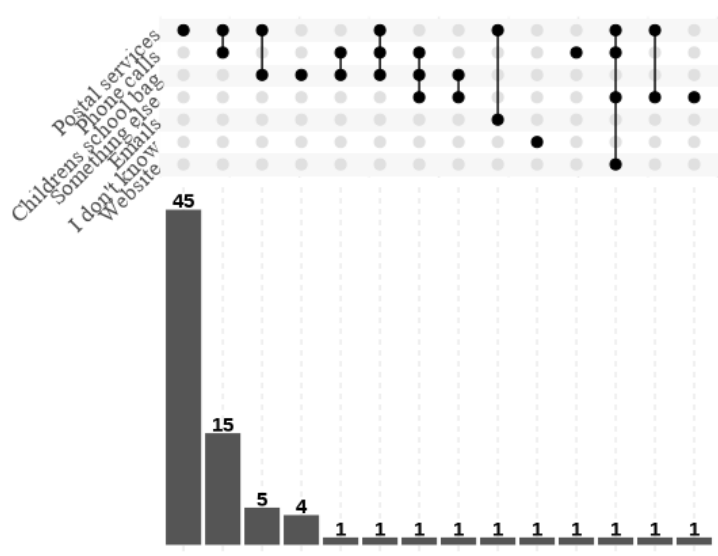

B) Do you share the results with all parents? $(\mathrm{N}=79)$

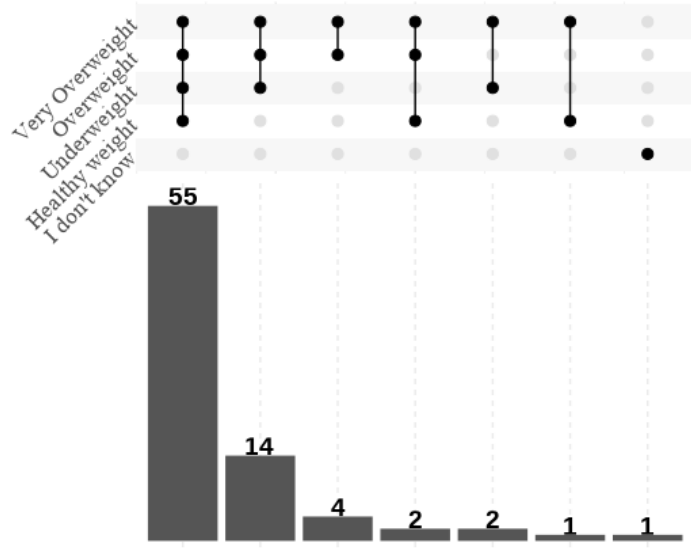


A)

How do you proactively follow-up with parents? $(\mathrm{N}=92)$

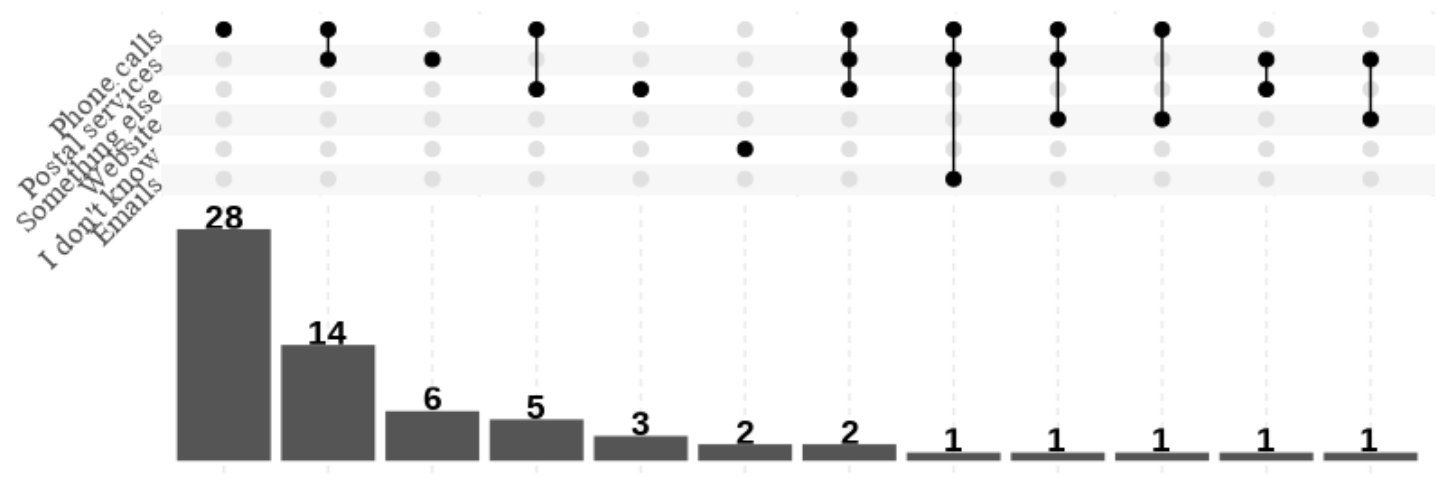

B)

Do you proactively follow-up with all parents? $(\mathrm{N}=65)$
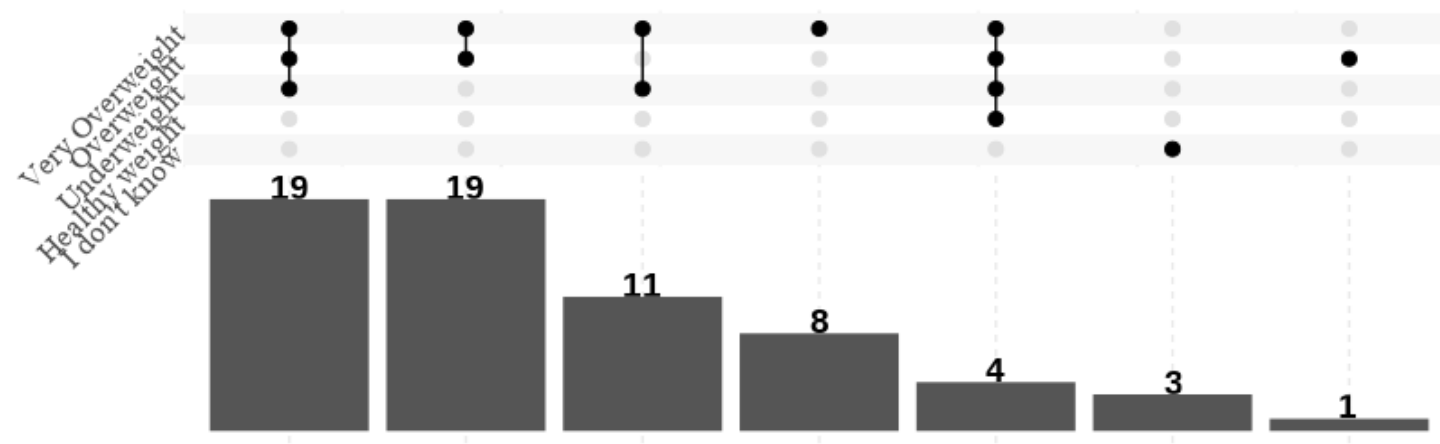

C)

Why do you not proactively follow-up with all parents? $(\mathrm{N}=82)$

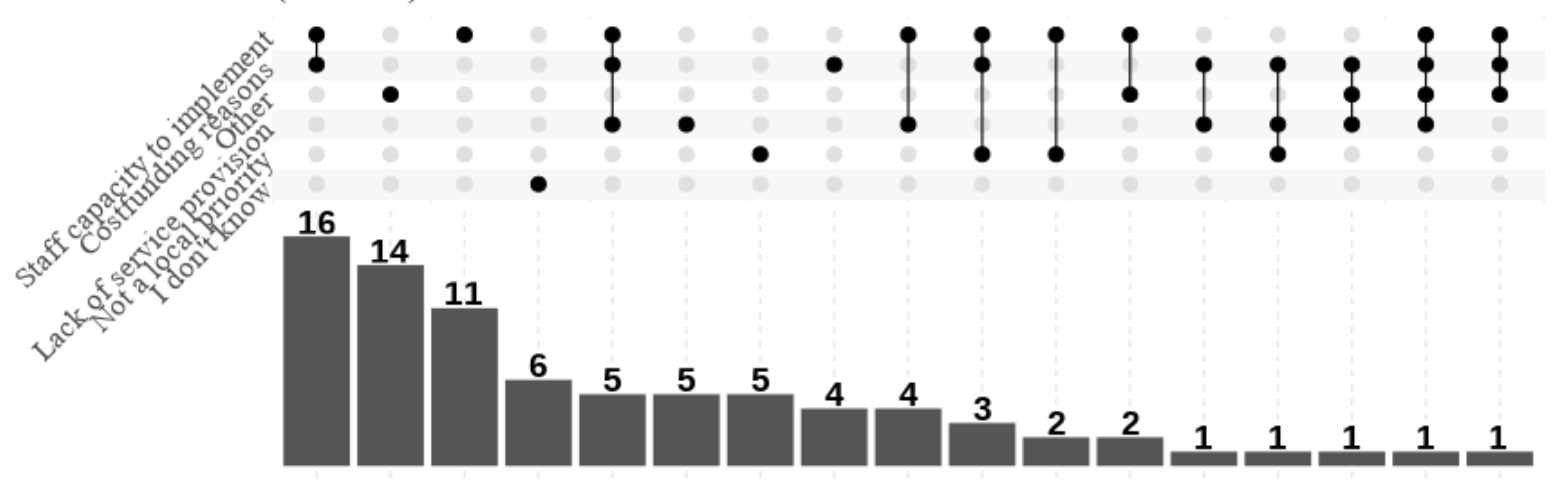


Which children are eligible to attend available services? $(\mathrm{N}=74)$
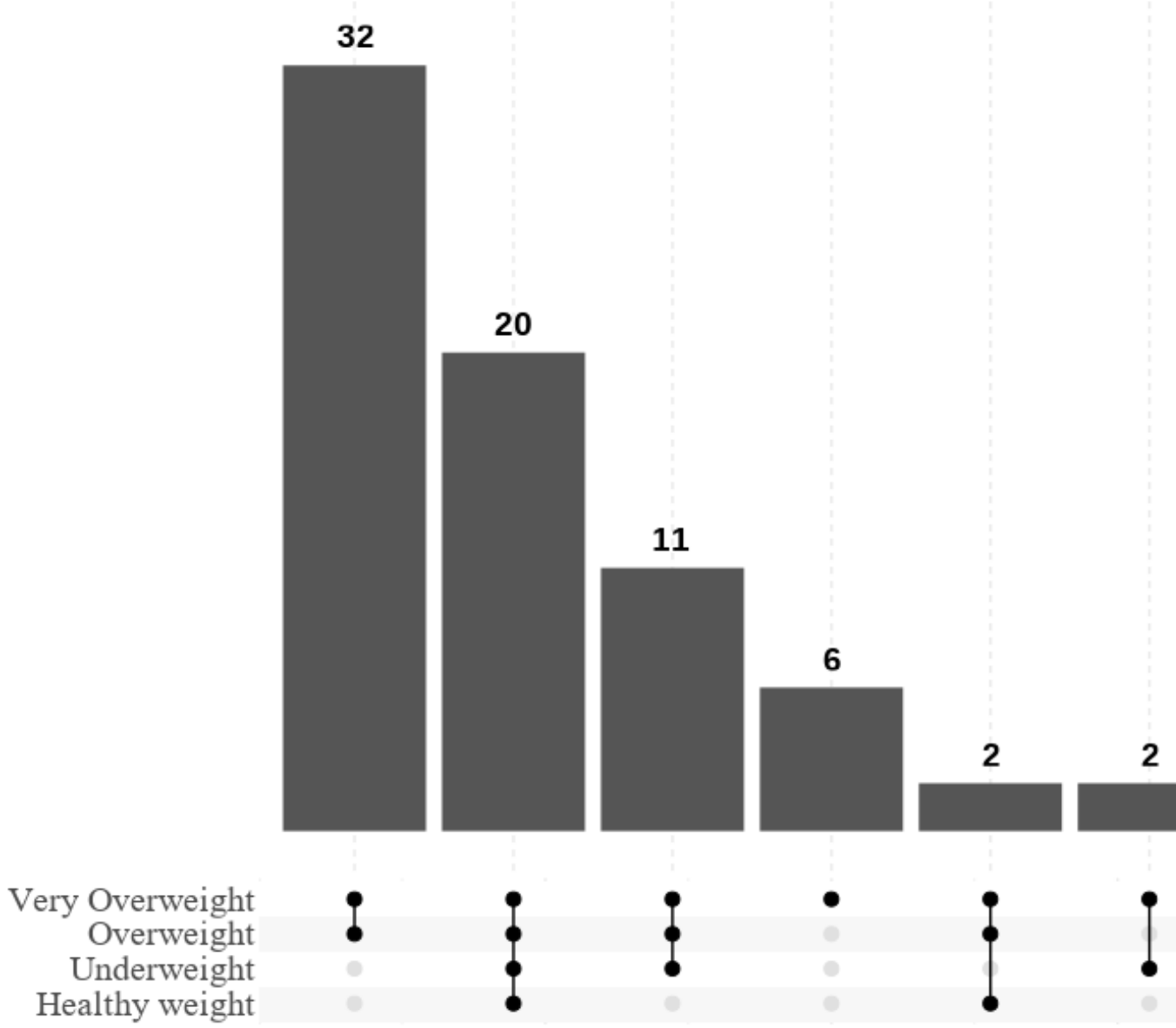